\title{
Computational Experiment Study on Selection Mechanism of Project Delivery Method Based on Complex Factors
}

\author{
Xiang Ding, ${ }^{1,2}$ Zhaohan Sheng, Jianguo Du, ${ }^{1,3}$ and Qian $\mathrm{Li}^{1}$ \\ ${ }^{1}$ School of Management and Engineering, Nanjing University, Nanjing 210093, China \\ ${ }^{2}$ School of Civil Engineering, The University of Sydney, Sydney, NSW 2006, Australia \\ ${ }^{3}$ School of Management, Jiangsu University, Zhenjiang 212013, China
}

Correspondence should be addressed to Qian Li; qianli@nju.edu.cn

Received 30 May 2014; Accepted 14 July 2014; Published 31 August 2014

Academic Editor: Zhichun Yang

Copyright (C) 2014 Xiang Ding et al. This is an open access article distributed under the Creative Commons Attribution License, which permits unrestricted use, distribution, and reproduction in any medium, provided the original work is properly cited.

\begin{abstract}
Project delivery planning is a key stage used by the project owner (or project investor) for organizing design, construction, and other operations in a construction project. The main task in this stage is to select an appropriate project delivery method. In order to analyze different factors affecting the PDM selection, this paper establishes a multiagent model mainly to show how project complexity, governance strength, and market environment affect the project owner's decision on PDM. Experiment results show that project owner usually choose Design-Build method when the project is very complex within a certain range. Besides, this paper points out that Design-Build method will be the prior choice when the potential contractors develop quickly. This paper provides the owners with methods and suggestions in terms of showing how the factors affect PDM selection, and it may improve the project performance.
\end{abstract}

\section{Introduction}

In the construction industry, project delivery method not only distributes the rights and responsibilities but also organizes the coordination between project owner and contractors [1]. PDM has a very important impact on the project strategic objectives, including project cost control, time planning, quality, and construction operations. Due to different modes relying on different situation, the project owners or project managers have to consider the experience and bias when they estimate PDM. More importantly, they need to seriously analyze many complex factors, such as construction environment, project features, ability of project owner, and ability of potential contractors.

There are some literatures mainly researching the relationship between PDM and project performance. Based on the comparative study on 351 cases in American construction industry, Konchar and Snvido [2] indicated the performance differences among cost control, quality, and time planning under different PDMs. Ling et al. [3] built a prediction model for project performance in Design-Build (DB) project and
Design-Bid-Build project by using multivariable method. In addition, there are some other researches on the decisionmaking methods to the selection of PDM based on different ways. The research of Mahdi [4] pointed out the indicators affecting the selection of PDM and the index weights with the help of analytic hierarchy process (AHP). Similarly, Mafkheri et al. [5] applied the improved AHP to establish selection model of PDM with multistandards and multilevels, as a result, the negative influence caused by the uncertainty from experts can be decreased. Luu et al. $[6,7]$ showed the mechanism of how project owner's demand, project features, and project environment affected the PDM selection based on the empirical conclusion. By using artificial neural network (ANN), Ling and Liu [8] measured and calculated the project performance in the DB projects. Chen et al. [9] also used ANN to find the cardinal rules on PDM selection. Unlike [8], [9] verified the validity of the model by using cases from China.

As mentioned above, PDM selection is very important to the project owner. Recent researches mainly focused on the foundation of index system. However, to establish 
a reasonable index system was usually affected by the rationality of indicators, the objective evaluation from experts, the validation of the large scale data, and so forth. Apart from this, recent researches did not describe the mechanism how these factors affect PDM selection. Therefore, this paper focused on two methods which are widely applied in construction industry, $\mathrm{DBB}$ and $\mathrm{DB}$. In this paper, project owner and project contractor are regarded as agents. Based on the analysis of behavior and decision-making rules of project owner agent and contractor agent, we established a computational experiment model and discussed how these factors, including project complexity, governance strength, and market environment, affect the PDM selection.

\section{Complex Factors Affecting PDM Selection}

Project delivery method defines the stakeholders involved in the implementing sequence of project design, procurement, and construction, and it also defines the benefits and risks of various stakeholders by the types of contract and design of system. As a result, we can use three dimensions to redefine the project delivery mode: (1) logical dimensions, including tasks in three stages: design, procurement, and construction, (2) dimensions of management subject, including project owner, design units, construction units, and the general contractor, and (3) contract dimensions, including general contract of design and construction and separate contract of design and construction. These elements can be combined into different PDMs according to different dimensions. For example, Design-Build contains two tasks: design and build; the general contractor is the subject manager, who signs a single contract with project owner on both design and build. In addition, there are some methods which are frequently used in the construction industry, including Design-Bid-Build, Engineering Procurement Construction (EPC), Turnkey, and Fast Track. In the early years, the traditional DBB mode occupies the majority share of the construction market in China. Currently, with the development of both engineering technology and management science, DB is gradually applied to a number of large-scale infrastructure constructions, such as Hong Kong-Zhuhai-Macao Bridge, which applied the DB to its most complex subproject, Island-Tunnel project. Therefore, this paper mainly focused on DBB and DB mode, and we assumed that project owner had to make a choice only between DBB and DB.

There are several advantages and disadvantages by using DB, compared with traditional DBB mode. The advantages include more close coordination relationship between design units and construction units, more specific boundary of rights and responsibilities, and better ability to cope with risks. The disadvantages include harder measurement of contributions of construction and design and harder maintenance of the individuality of design. In summary, any method has specific application conditions. Before project owners decide to choose PDM, they have to analyze the specific construction environments (not only the natural environment but also the political environment and the economic environment) and construction demands seriously in order to find the balance among environment, feature, and method.

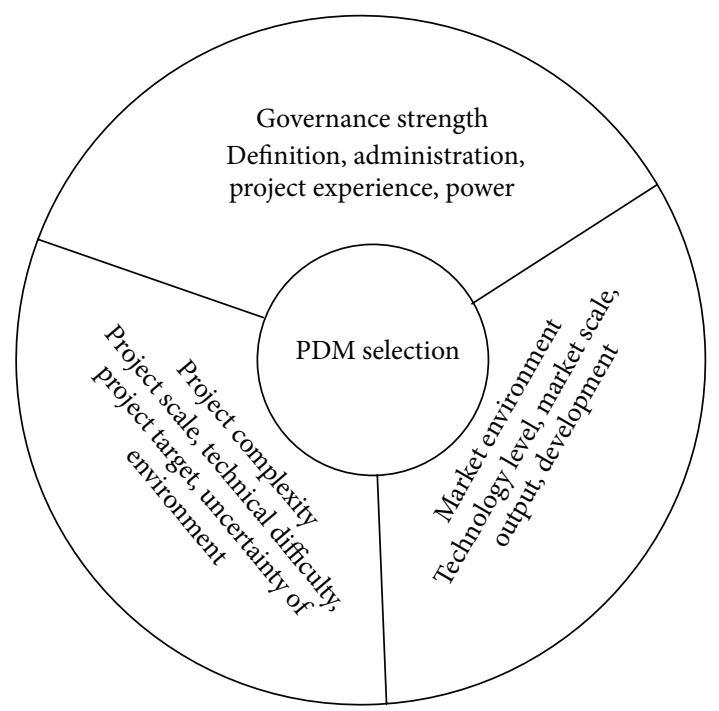

FIgure 1: Complex factors affecting PDM selection.

Ibrahim suggested that the project owner needs to consider 7 aspects, including owner's feature, project's feature, design feature, legal system for contract, the ability and bias of potential contractors, project risk, and compensation [4]. Similarly, Chen inclined to project target (time planning, cost control, and project risk), project feature (type, scale, and complexity), owner's feature, contractor's ability, and project environment (construction industry, technology environment, and legal system) affecting the project delivery planning [9].

Here, we mainly discuss factors from inside and outside of the project. We establish a computational experiment model to revise how project complexity, governance strength, and market environment affect project owner in selecting project delivery method, Design-Build, or Design-Bid-Build, as seen in Figure 1. Specifically, we use 4 items, including project scale, technical complexity, construction environment, and construction targets, to describe the project complexity. As for governance ability, project owners have different abilities to govern. For DBB mode, the project owner does have the ability not only to revise the plans of both contractor and designer, but also to perform a delicate balancing act between the different sides in the conflict. For DB mode, the project owner should definitely have demands and the ability to choose appropriate contractors; besides, the project owner has to give the general contractors enough rights while transferring project risks to them. Finally, how to refine the market environment: there are many different angles to define market environment, such as the angle of economy and technology. In this paper, we mainly discuss the market consisting of different levels of cons;2truction company, and we focused on whether the growth of market can affect the PDM'selection. Accordingly, technology level, market scale, output, and development are indispensable to describe market environment. In addition, we use resource integration, internal coordination, and technical innovation to describe contractor's ability. 


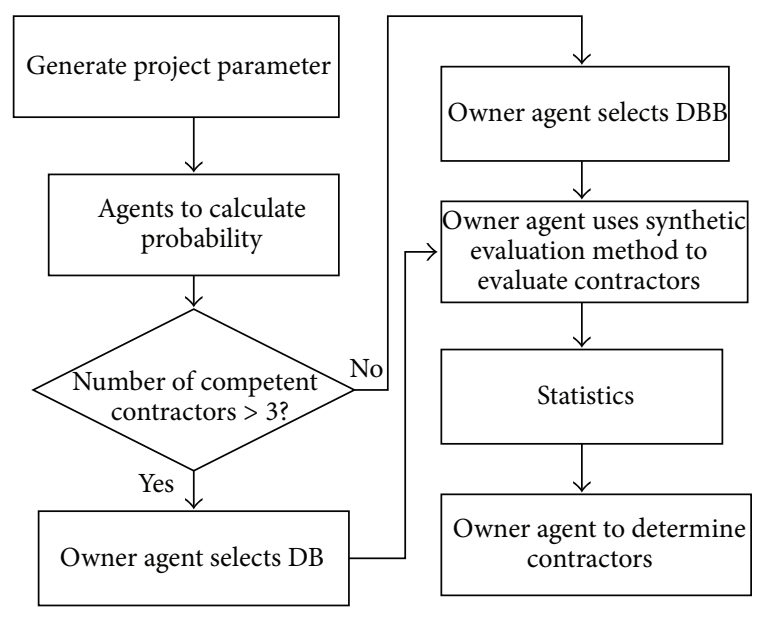

FIGURE 2: Flowchart of owner's interactive process.

\section{Multiagent Design}

3.1. Owner Agent. We consider a model which includes one project owner and 50 potential contractors (both designers and constructors). Owner has three activities in the experiment.

The decision-making process for project owner is set in this experiment as Figure 2.

(1) Market Investigation. The project owner has to estimate the potential contractors before bidding. In this model, we considered potential contractors as competent contractors depending on whether contractors' properties are equal to the project complexity index $\chi$ or not. When the amount of competent contractors is up to 3 , the DB mode will be; available in the owner agent's optional list.

(2) Choosing Bidding Mode. At the scene when DB mode can be applied, the probability for owner to select DB mode is calculated as follows:

$$
P_{\text {bidding }}=\varepsilon \chi+\delta(1-\psi) .
$$

We use $\varepsilon$ as the weight of project complexity and $\delta$ as the weight of governance strength. $\psi$ stands for the governance strength. If the project owner selects DBB mode, the project owner will require the potential bidders to join design and construction bidding, respectively.

(3) Evaluating and Determining. In this model, we use synthetic evaluation method to calculate the weighted average value of each bidder and project owner on the design and construction task. Contractor $i$ got the initial value to describe their ability randomly at the beginning of each experiment, and synthetic score of market environment can be calculated by weighted average value between project targets and contractor's abilities.

3.2. Contractor Agent. Contractors have two activities in this model.

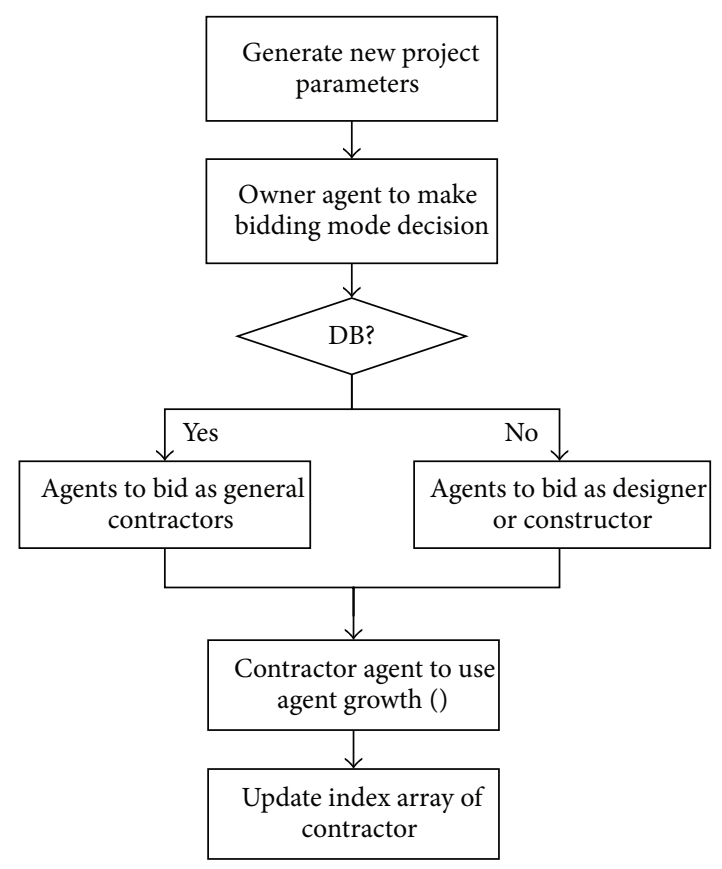

FIGURE 3: Flowchart of contractor's interactive process.

The decision-making process of contractor agent can be described in Figure 3.

(1) Bidding. According to the selected bidding mode by the project owner, the contractor agent chooses different strategies. If the project owner selects the DB mode, the contractor agents submit entire design and build values as general contractor. Otherwise, as to DBB mode, the contractor will choose design bidding or construction bidding relying on the higher value.

(2) Growing Up. The contractors have the ability to grow up after each experiment, and the value of contractor's ability will increase. In this paper, we build a growth model to make contractor agents increase their value of ability after each experiment tick. In the model, self-growth of agent's ability can be described as formula

$$
\frac{d X_{i}(t+1)}{d t}=r_{\text {growth }}(t) X_{i}(t)\left(1-\frac{X_{i}(t)}{k_{i}}\right) \text {. }
$$

$X_{i}(t)$ stands for index array of contractor $i$ 's ability at the $t$ tick. In the construction industry, there will be a development bottleneck for each enterprise based on enterprise theory. Therefore, we use $k_{i}$ to describe the maximum ability once a contractor can reach. $k_{i}$ will be set up at the beginning and will stay unchangeable until the end of experiment. The market will get growth and the growth rate is $r_{\text {growth }}$.

\section{Experiment Scenarios and Initial Settings}

In order to make the model get to work, we adopt Netlogo to implement the agent-based modeling and simulation. The initial parameters are shown in Table 1 . The initial value of contractors' ability follows the Gaussian distributions. 
TABLE 1: Initializations of experiment parameters.

\begin{tabular}{lcc}
\hline Parameters & Standing for & Scale \\
\hline$\varepsilon$ & The weight of project complexity & 0.5 \\
$\delta$ & The weight of project governance strength & 0.5 \\
$T_{\text {growth }}$ & Growth times of contractor & 50 \\
$r_{\text {growth }}$ & Growth rate of contractor & Random float number between 0 and 0.1 \\
$\alpha_{\text {des }}$ & The design ability value of designer & Random float number between 0.5 and 1 \\
$\beta_{\text {des }}$ & The construction ability value of designer & Random float number between 0 and 0.1 \\
$\alpha_{\text {cons }}$ & The design ability value of constructor & Random float number between 0 and 0.1 \\
$\beta_{\text {cons }}$ & The construction ability value of contractor & Random float number between 0.5 and 1 \\
$U$ & The weight of design & {$[0.15,0.075,0.075,0.075,0.15]$} \\
$V$ & The weight of construction & {$[0.175,0.105,0.105,0.105,0.055]$} \\
\hline
\end{tabular}

We focus on the impacts of different complex factors on the PDM selection. First, we research on the impact of the project complexity. The method is that we change the parameter of project complexity in each experiment and keep other parameters, such as market environment, constant during all experiments. We change the values of project complexity from 0.1 to 0.9 to revise the selection probability. Then, we run the experiments to revise the relationship between governance strength and PDM selection by using the same method as the first one.

Finally, we build two comparative experiment scenarios to study the relationship between the market environment and PDM selection. The contractor's growth is ignored in one experiment whilst the contractor's growth is considered in another experiment.

In order to acquire reliable data and to decrease the deviation of the experiment results, each experiment will be repeated ten times and we will use the average level $[10,11]$.

\section{Experiment Results and Discussions}

5.1. The Impact of Project Complexity. Project complexity affects the project delivery method mainly through two aspects. For one thing, the complexity of the particular project directly determines whether to select Design-build mode, due to risk transfer from project owner to general contractors, and it also can be considered as a risk reduction. For another thing, project complexity affects project owner's power of administering, including construction contracts, time planning, construction operations, estimating process, and construction labor [12].

In this experiment, the abilities of both owner and contractor remain unchanged, and the parameter of project governance strength is set as 0.5 during the whole experiment. Moreover, both designers and constructors not grow up.

For the given values, the average ability of construction contractor agents is 0.751 and of designers is 0.749 , we make the experiment run 100 times and each experiment repeats 10 times to acquire the average data for statistical analysis, and Figure 4 shows the results.

Analysed from Figure 4, the following conclusions and discussions can be drawn.

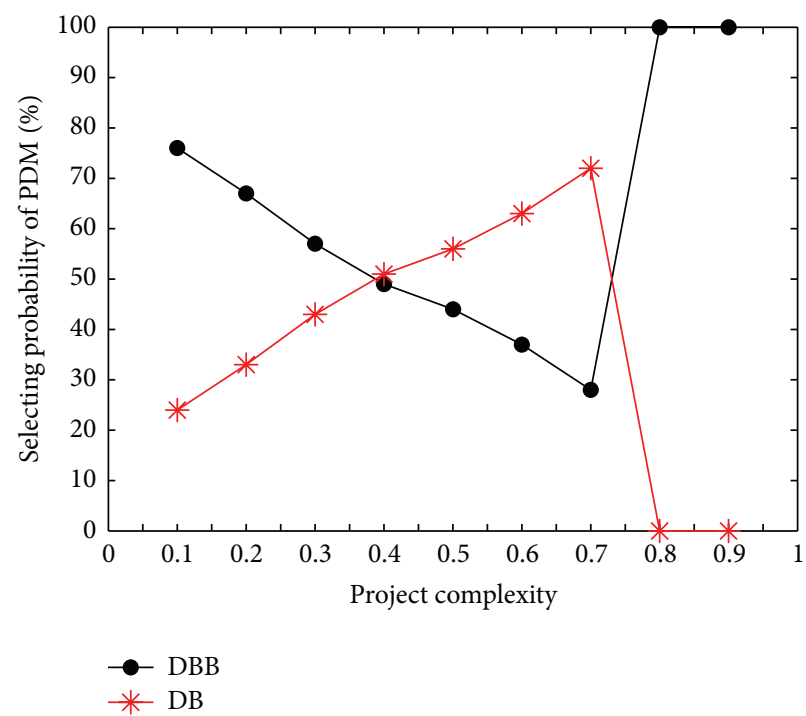

FIGURE 4: PDM selection under different project complexities.

(1) Project owner inclines to Design-Bid-Build mode in simple or not complex project. When the complexity degree of a project is less than 0.5 , the project is easy to be designed and built relying on the existing engineering technology and management. Besides, the project owner has enough experience and ability to administrate the building process. In the low-risk and regular project, case study in China has shown that the project owner/manager is more likely to choose DBB mode to enforce their administration on the whole construction period and the entire process and, in this way, the project can be implemented within high quality and low cost [13].

(2) With the increase of project complexity degree, project owner is more likely to choose Design-Build mode. When the complexity degree of a project is between 0.5 and 0.8 , project owner needs high ability to control the building process and to coordinate the multirelationship (such as designer, different contractors, consultant, and even the local government) 
due to the increase of the project scale, the difficulty of construction technology, and environment uncertainty. Particularly, in many countries, the contractors are usually more professional than the project owners. As a result, project owner inclines to allocate more tasks of project management to experienced and competent contractors in order to control the budget and risk so well to reduce the project changes and claims [14].

(3) Project owner prefers to select DBB mode in complex megaprojects. To be specific, when the complexity degree is up to 0.8 , this project only can be realized by general contractors with extraordinary qualified credential in both design and build. It is very hard to find a construction company or a joint venture consisted of several companies including designer, constructor, and consultant, to deal with the technical and management difficulty. Therefore, project owner has to decompose the project into different modules and subprojects and, then, project owner finds the qualified contractors to fulfill the decomposed project under DBB mode.

5.2. The Impact of Governance Strength. How to evaluate a good project owner: first of all, a good owner has to define the project target clearly in order to organize the implementation effectively. Moreover, the capacity to estimate the quality of design and to coordinate the conflicts during the whole construction period is inevitable [15]. Finally, a good owner can deal with emergency and risk properly and efficiently.

During the experiment, we keep project complexity and market environment unchanged; the average ability of constructor and designer remains 0.742 and 0.756 respectively. The parameter of project complexity is set as 0.5 and both designers and constructors do not grow up after each experiment.

Figure 5 shows the probability for owners to decide which project delivery mode to choose.

As shown in Figure 5, project owners rely on DB mode to a great extent when they do not have enough ability to handle the project management. All of the involved contractors including designer, constructor, supervisor, and consultant take responsibility directly to project owner according to the contract, and project owner needs to coordinate different sections and to administrate the whole construction procedure [16].

However, general contractors are in charge of the design and build process under $\mathrm{DB}$ mode, and project owner has to revise the job of just one general contractor.

In summary, with the impact of enhancement of governance strength, project owner will have a strong desire to participate in every procedure, and this makes DBB mode more and more popular to project owners.

5.3. The Impact of Market Environment. The former two experiments are based on the ignoring the market growing. As a matter of fact, contractors not only achieve the growth in construction technology and project management, acquiring

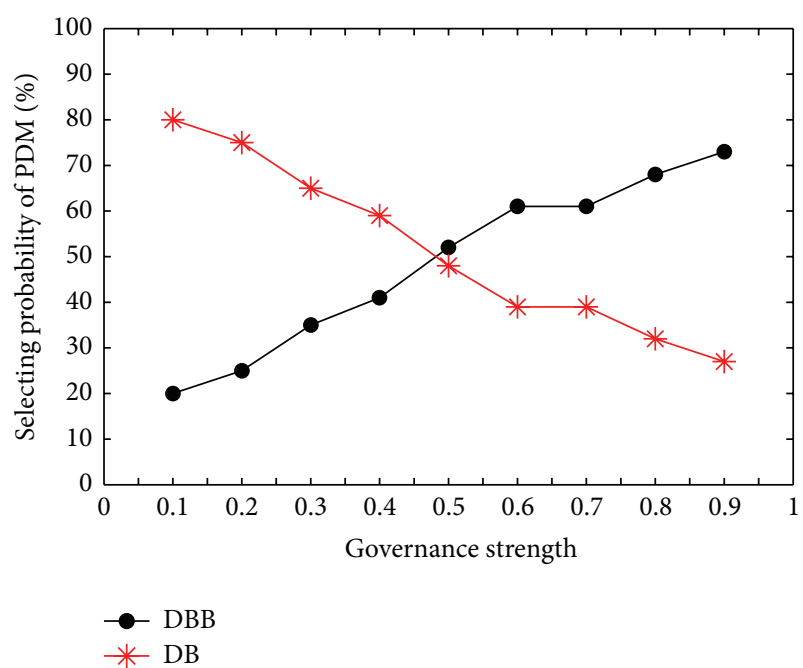

FiguRE 5: PDM selection under different governance strength.

abundant experience, but also cultivate talents in different construction field. Even contractors fail in project bidding, yet they will recognize their inadequacy better, and then they will also grow up. Indeed, it is very useful to revise how the average level of construction industry affects PDM selection. For this purpose, we repeat the former two groups of experiments on the basis of adding self-growth model, and then we compare the new results with the former experiments.

\subsubsection{The Impact of Project Complexity under Market Growing.}

We let each index degree of contractor's ability increase every 50 experiment ticks and repeat the experiment process as in Section 5.1. Besides, in order to estimate the relationship between growth rate and PDM selection, we set different values and run three groups of experiments. To be more precise, all of the three groups share the same parameters except $r_{\text {growth }}$ which stands for contractor's growth rate. The growth rate changes from $0,0.05$ to 0.1 , meaning remainstagnant, slow-growth, and fast-growth, respectively.

We can see from Figures 6(a), 6(b), and 6(c) that, when remain-stagnant agents compared with growth agents, $\mathrm{DB}$ mode has the chance to be chosen by the project owner while it is never considered in the highly complex projects within the complexity degree up to 0.8 . With the help of practices, contractor's ability improved constantly. In this way, a number of experienced contractors with high reputation and excellent performance emerged in construction industry [17]. These enterprises have the ability to become DB general contractors, and they can reduce the risk and cost if project owner decides to use DB. In consideration of potential benefits from project time control and quality, project owner takes DB mode as alternative solutions.

Comparing slow-growth agents with fast-growth agents, as seen in Figures 6(b) and 6(c), project owner will incline to select DB mode even in the most complex project. Actually, project owner usually does not have enough confidence to handle rather complex project, especially in so-called 


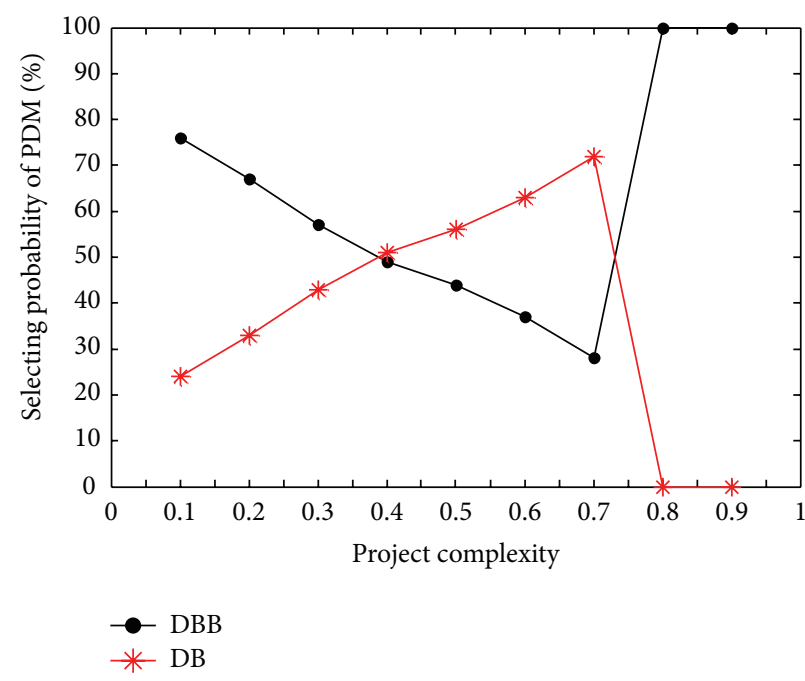

(a) $r_{\text {growth }}=0$

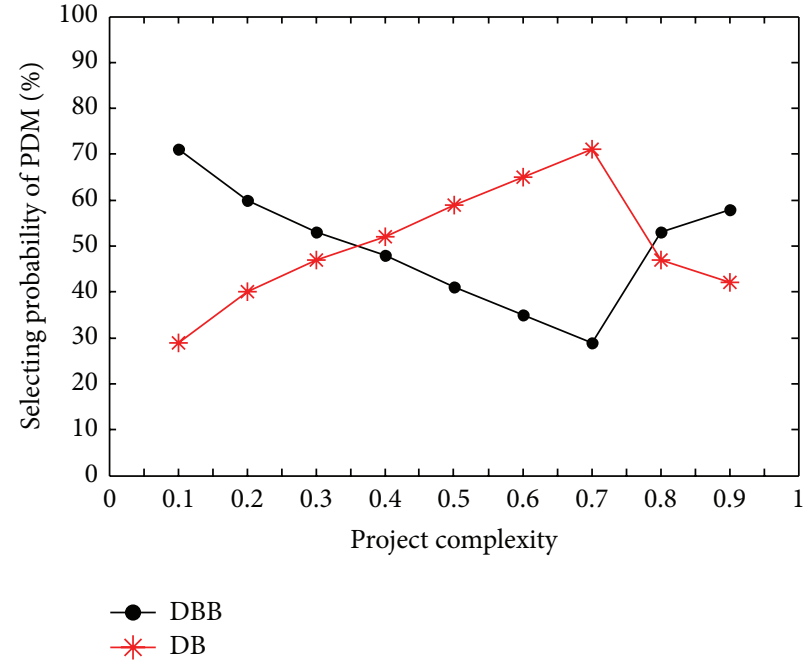

(b) $r_{\text {growth }}=0.05$

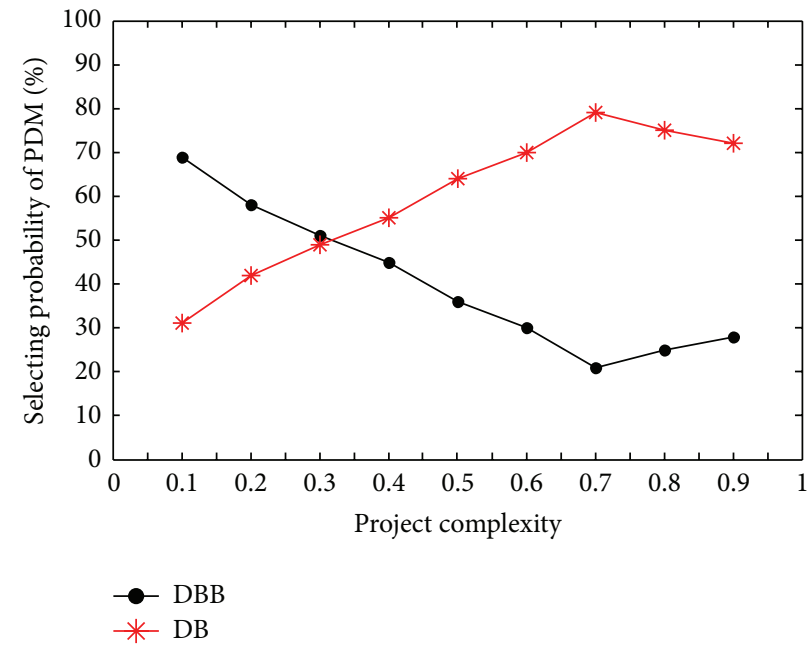

(c) $r_{\text {growth }}=0.1$

FIGURE 6: PDM selection under different project complexities considering market growing.

unparalleled megaprojects, and the project owner will hope to transfer management risk to contractors in order to reduce project risk. The faster the contractor grows up, the more likely the ability of contractor administrates the complex project. As a result, project owner will be apt to use DB mode while there are fast-growth contractors in construction industry.

5.3.2. The Impact of Governance Strength under Contractor's Self-Growth. Similar to experiment procedure in Section 5.3.1, we also repeat experiments in Section 5.2 and get three groups of experiment results.

Figure 7 shows probability of project owner whether to choose $\mathrm{DB}$ or $\mathrm{DBB}$ as project delivery mode under different growth rate of contractor agents. It is undoubtedly that project owners used to choose DB for managing the building process when their ability level under about 0.5 , or we can define these project owners as weak owners, from
Figures 7(a), 7(b), and 7(c). For weak owners, they do not have enough experience and knowledge to administrate the whole building procedure. As mentioned earlier in this paper, weak owners need contractors who can undertake much of the risk of project management.

When contract agents grow up, the value describing their ability will increase continuously. Therefore, there will be many contractors who can successfully act as designers, builders, and even general contractors. For strong owners (with the ability level up to 0.5 ) who can easily administrate the project delivery, it is difficult for them to determine which method is the best choice, as we can see from the comparison between Figures 7(a) and 7(b). Project owner will make the decision of PDM according to their preference and experience.

When the value of governance strength rises at a certain level, the probability of selecting DB method and DBB mode are not far from each other. What is the key factor affecting 


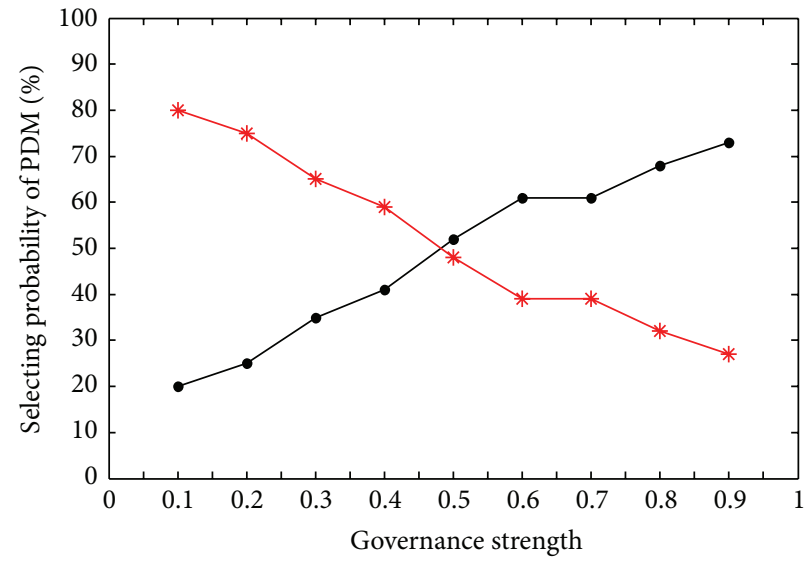

$\rightarrow \mathrm{DBB}$

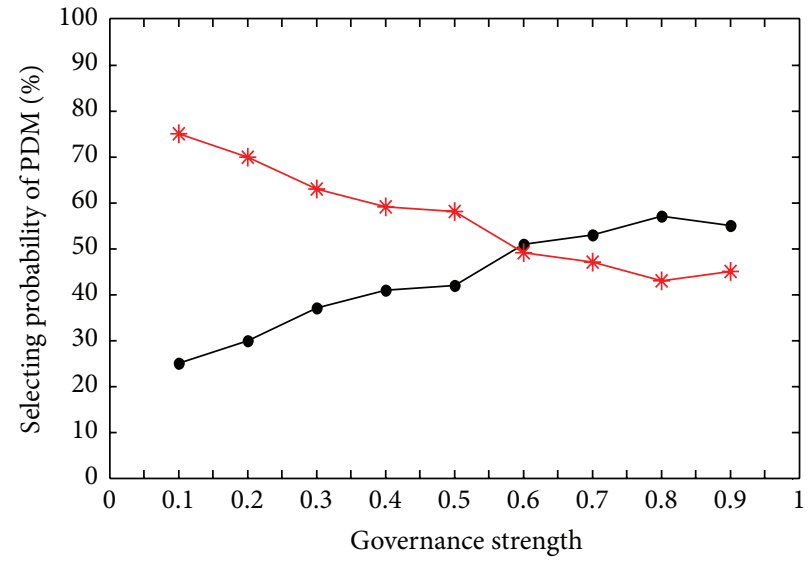

$\bullet$ DBB

$\rightarrow$ DB

(a) $r_{\text {growth }}=0$

(b) $r_{\text {growth }}=0.05$

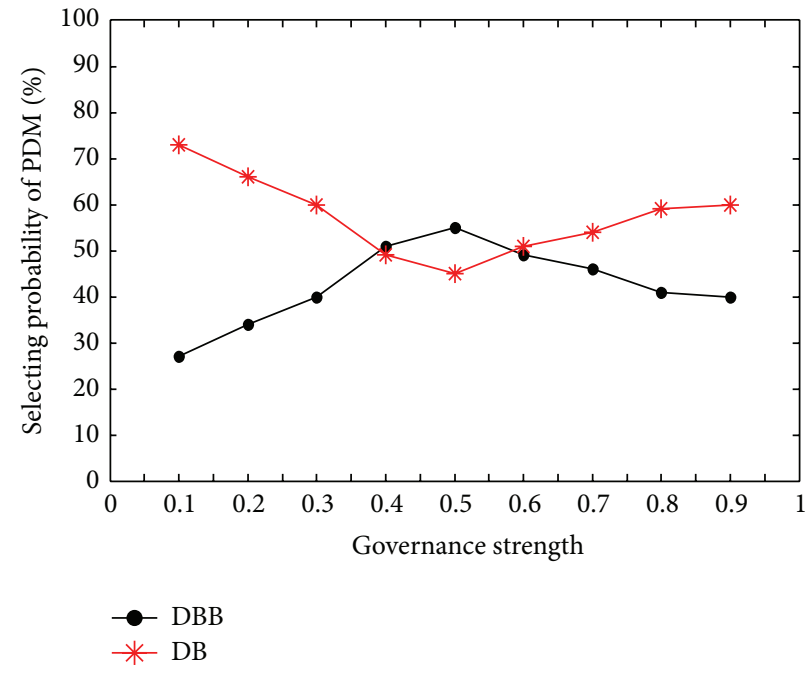

(c) $r_{\text {growth }}=0.1$

FIGURE 7: PDM selection under different governance strength considering market growing.

decision of the project owner? From Figures 7(b) and 7(c), it is obvious that the project owner is more likely to select DB mode when the contractor agents in this experiment have higher growth rate. Compared with slow-growth contractors, fast-growth contractors have many advantages at planning, monitoring, coordinating, controlling, communication, and decision-making [18]. All of these advantages greatly help project owner reduce the project risk and ease their burden. Therefore, in order to achieve the success of project efficiently, DB mode become project owner's first choice when the potential companies develop quickly in the construction industry.

Based on the former experiments, we may find that market environment is a crucial factor affecting PDM selection. Above all, in order to promote Design-Build project delivery method, it is very important for companies to develop their ability by self-growth.

\section{Conclusions}

The scientific and reasonable selection of project delivery method is crucial for project owners to deal with project complexity and to achieve project success. This paper assumes that project owner focus on many factors that may affect the PDM selection, and these factors and their interrelationships contribute to a complex factor system. We establish an agent-based simulation model in order to analyze the selection mechanism of project delivery method based on computational experiment. And we revise the relationship between given factors and selection probabilities by statistical analysis of different groups of experiment results. This paper mainly discusses three factors, including project complexity, governance strength, and market environment.

Experimental results show that project complexity, governance strength, and market environment have significant 
influences on PDM selection. Project owners are more likely to use Design-Build to deliver the project at the condition that their abilities are weak and the projects are complex. Otherwise, when project owners have the ability to administrate project procedure, they are willing to be in charge of every process of design and building, so they prefer to choose DBB method. In addition, the increasing ability of contractor reduces the risk for project owners to deliver the project by $\mathrm{DB}$; thus they have greater preference to choose DB general contractors. Under different type of construction market, project owner prefer Design-Build method to DesignBid-Build method when the potential contractors develop quickly.

In summary, there are some other factors that should be revised, although we have obtained some useful results about PDM selection. In the near future, we will study more micro factors that affect project owner selecting project delivery modes.

\section{Conflict of Interests}

The authors declare that there is no conflict of interests regarding the publication of this paper.

\section{Acknowledgments}

The authors are indebted to editors and the anonymous reviewers for their insightful comments and beneficial suggestions, which help ameliorate the quality of this paper. This work is supported by the National Natural Science Foundation of China (Grant no. 71390521, no. 71301062, no. 71301070, no. 71390521 , no. 71101069 , no. 71171099, and no. 71001049) and the National Eleventh-Five Year Research Program of China (Grant no. 2011BAG07B05).

\section{References}

[1] American Society of Civil Engineers, Quality in the Constructed Project: A Guide for Owners, Designers and Constructors, ASCE Publication, Reston, Va, USA, 2000.

[2] M. Konchar and V. Sanvido, "Comparison of U.S. project delivery systems," Journal of Construction Engineering and Management, vol. 124, no. 6, pp. 435-444, 1998.

[3] F. Y. Y. Ling, S. L. Chan, E. Chong, and L. P. Ee, "Predicting performance of design-build and design-bid-build projects," Journal of Construction Engineering and Management, vol. 130, no. 1, pp. 75-83, 2004.

[4] I. M. Mahdi and K. Alreshaid, "Decision support system for selecting the proper project delivery method using analytical hierarchy process (AHP)," International Journal of Project Management, vol. 23, no. 7, pp. 564-572, 2005.

[5] F. Mafakheri, L. Dai, D. Slezak, and F. Nasiri, "Project delivery system selection under uncertainty: multicriteria multilevel decision aid model," Journal of Management in Engineering, vol. 23, no. 4, pp. 200-206, 2007.

[6] D. T. Luu, S. Thomas Ng, and S. E. Chen, "A case-based procurement advisory system for construction," Advances in Engineering Software, vol. 34, no. 7, pp. 429-438, 2003.
[7] D. T. Luu, S. T. Ng, and S. E. Chen, "Formulating procurement selection criteria through case-based reasoning approach," Journal of Computing in Civil Engineering, vol. 19, no. 3, pp. 269-276, 2005.

[8] F. Y. Y. Ling and M. Liu, "Using neural network to predict performance of design-build projects in Singapore," Building and Environment, vol. 39, no. 10, pp. 1263-1274, 2004.

[9] Y. Q. Chen, J. Y. Liu, B. Li, and B. Lin, "Project delivery system selection of construction projects in China," Expert Systems with Applications, vol. 38, no. 5, pp. 5456-5462, 2011.

[10] S. M. R. Loghmanian, H. Jamaluddin, R. Ahmad, R. Yusof, and M. Khalid, "Structure optimization of neural network for dynamic system modeling using multi-objective genetic algorithm," Neural Computing and Applications, vol. 21, no. 6, pp. 1281-1295, 2012.

[11] M. Qingfeng, D. Jianguo, L. Zhen, and C. Jingxian, "Evolutionary dynamics of sales agents promotional effort on small-world networks," Neural Computing and Application, vol. 24, no. 1, pp. 3-12, 2014.

[12] W. H. Daniel and W. W. Ronald, Construction Management, John Wiley \& Sons, New York, NY, USA, 4th edition, 2010.

[13] F. Y. Y. Ling, S. P. Low, S. Q. Wang, and H. H. Lim, "Key project management practices affecting Singaporean firms'project performance in China," International Journal of Project Management, vol. 27, no. 1, pp. 59-71, 2009.

[14] S. M. Levy, Design-Build Project Delivery: Managing the Building Process from Proposal through Construction, The McGraw-Hill, New York, NY, USA, 2006.

[15] F. Y. Y. Ling and B. H. M. Poh, "Problems encountered by owners of design-build projects in Singapore," International Journal of Project Management, vol. 26, no. 2, pp. 164-173, 2008.

[16] S. Lu and G. Hao, "The influence of owner power in fostering contractor cooperation: evidence from China," International Journal of Project Management, vol. 31, no. 4, pp. 522-531, 2013.

[17] J. Huang, "Study on the problem of slowness in pushing the project general contracting mode in Chinese construction industry: the perspective of institutional change," East China Economic Management, vol. 25, no. 7, pp. 65-68, 2011.

[18] A. Hamimah, B. Fauziah, S. Azizan, and A. Mohd, "Success factors of design and build projects in public universities," Procedia-Social and Behavioral Sciences, vol. 35, pp. 170-179, 2012. 


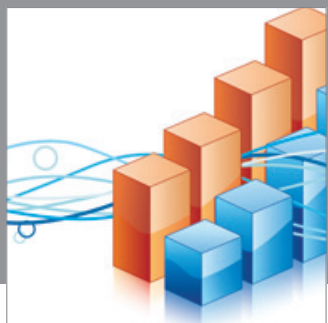

Advances in

Operations Research

mansans

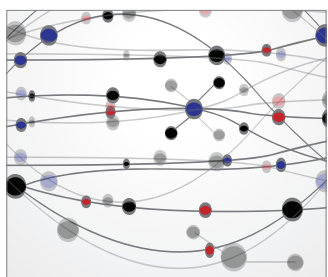

The Scientific World Journal
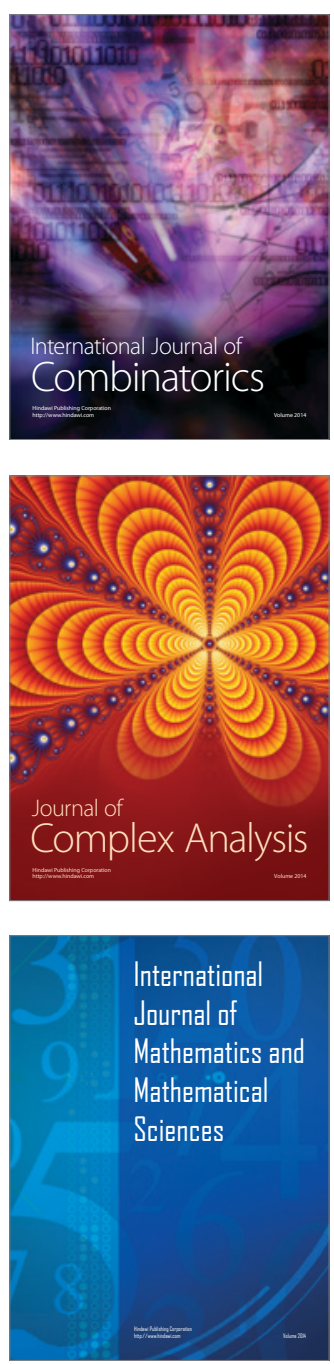
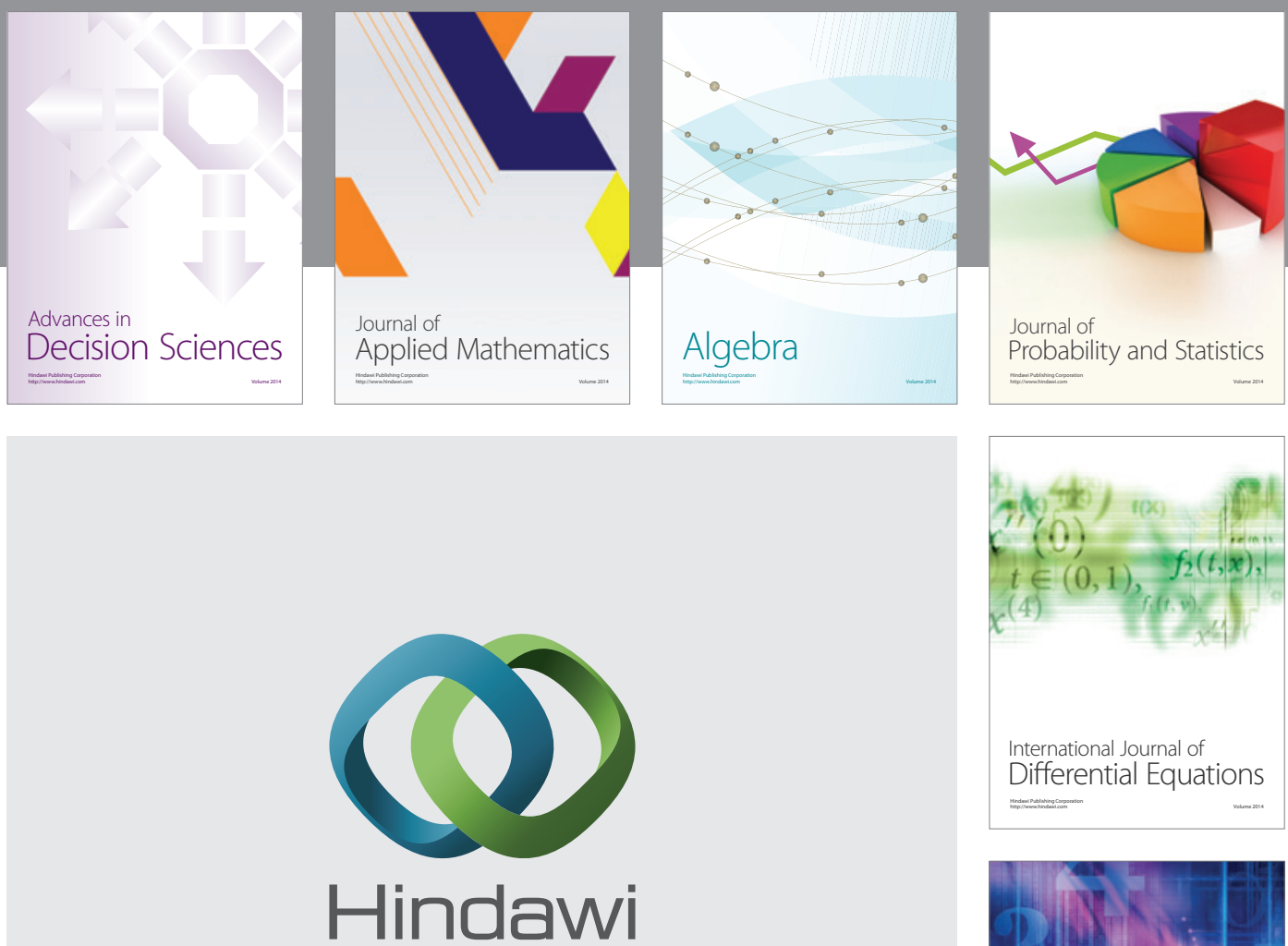

Submit your manuscripts at http://www.hindawi.com
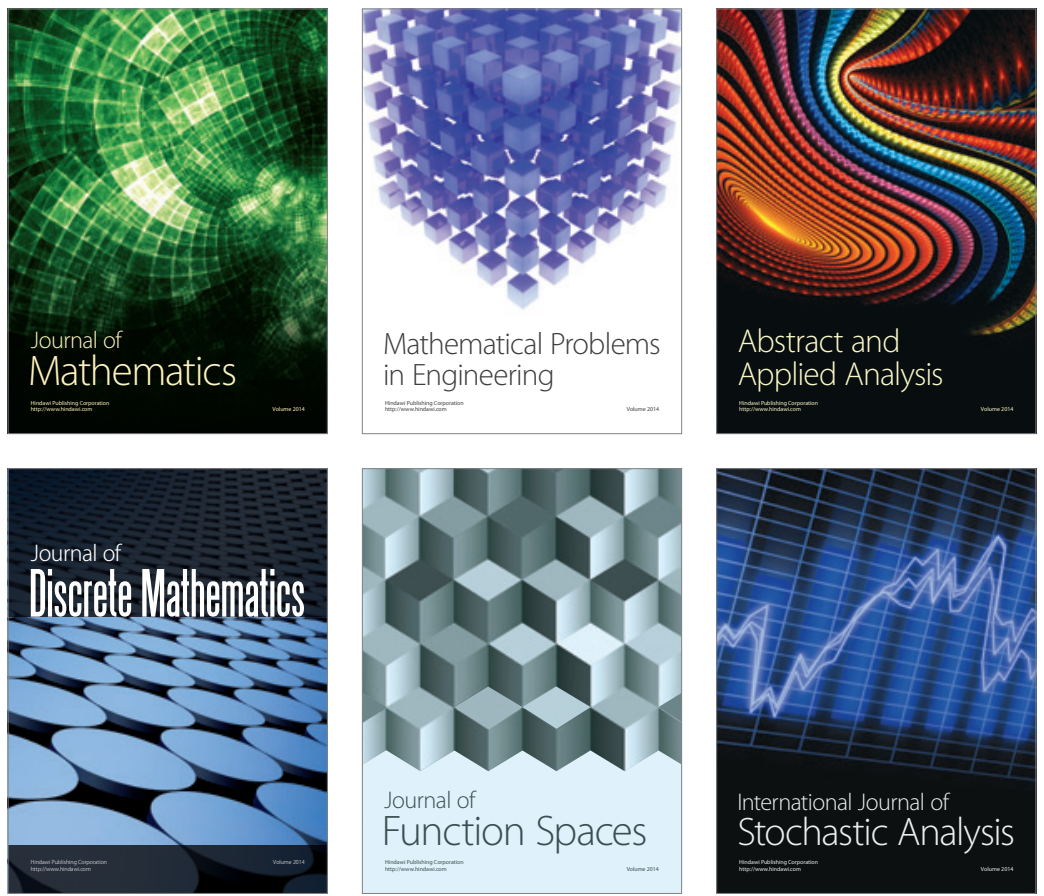

Journal of

Function Spaces

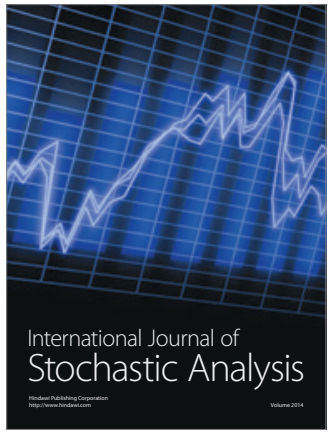

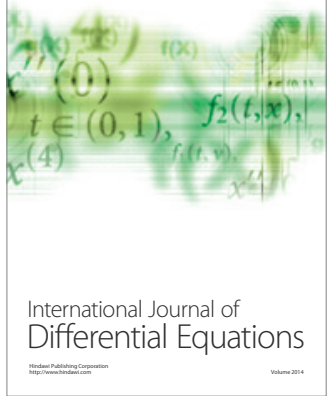
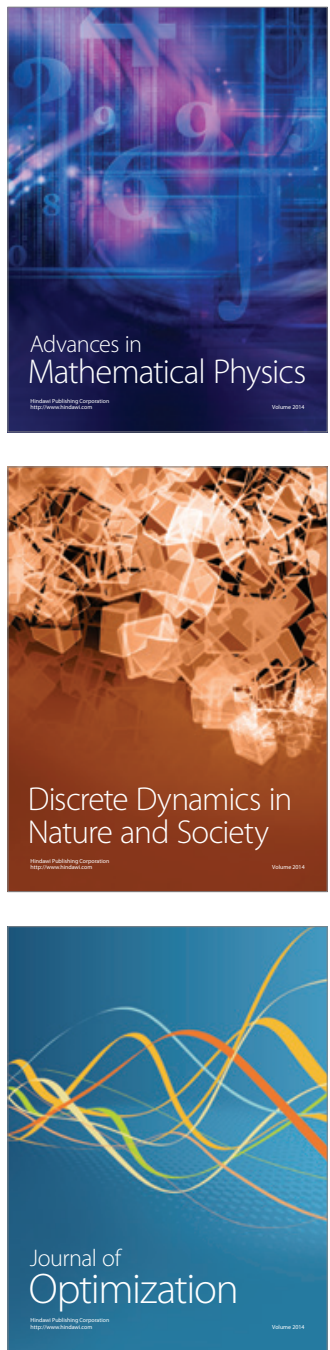